\title{
Investigating the role of ICT intervention in grassroots innovation using structural equation modelling approach
}

\author{
SONAL SINGH $^{1, *}$, BIRUD SINDHAV $^{2}$, DALE EESLEY $^{2}$ and BHASKAR BHOWMICK ${ }^{1}$ \\ ${ }^{1}$ Rajendra Mishra School of Engineering Entrepreneurship, Indian Institute of Technology Kharagpur, \\ Kharagpur 721 302, India \\ ${ }^{2}$ Department of Marketing and Entrepreneurship, University of Nebraska, Omaha 68182, USA \\ e-mail: sona.singh610@gmail.com; bsindhav@unomaha.edu; deesley@unomaha.edu; \\ bhaskar@see.iitkgp.ernet.in
}

MS received 25 August 2017; revised 1 September 2017; accepted 4 September 2017; published online 18 June 2018

\begin{abstract}
Research on information communication technologies (ICT) for entrepreneurship development is burgeoning, yet our understanding of the use of ICT in support of grassroots innovation remains unclear. This paper examines the moderating role of the use of ICT on the relationship between grassroots innovation (GRI) and entrepreneurial success (ES). The study involved 400 grassroots entrepreneurs selected from three states in India, and the moderating effect of the use of ICT was analysed using moderated structural equation modelling. The results revealed that the use of ICT partially moderates the relationship between the new learning practices and economic benefits. It also partially moderates the relationship between local solution and economic benefits, but it fully moderates the relationship between networking capabilities and economic benefits, where the relationship is stronger when the use of ICT is high. Furthermore, the study found that the use of ICT does not moderate the relationship between new learning practice and non-economic benefits, relationship between local solution and non-economic benefits and relationship between networking capabilities and non-economic benefits.
\end{abstract}

Keywords. Information communication technologies (ICT); grassroots innovation; structural equation model; entrepreneurship development.

\section{Introduction}

Today, ICT-enabled interventions, especially the internet and mobile revolution have drastically changed the daily norm [1]. Instant data access, social media interactions, e-commerce platforms, mobile communication and smart devices have facilitated the fast conversion of offline process to online [2]. In a knowledge-driven and globalized world, ICT acts as a critical tool for job creation and economic growth of a nation [3]. However, majority of grassroots innovators struggle to make both ends meet because of their underutilized GRI based entrepreneurial potential [4]. Nevertheless, in recent past the phenomenon has changed towards the better, as more grassroots innovators are grasping the potential of using ICT as a tool to access market information, production techniques and financing opportunities which help in transforming their innovation into entrepreneurial activities.

Grassroots innovators are uniquely suited to excel in entrepreneurial activities because of their innovation potential, embedded traditional knowledge and skill [4, 5].

*For correspondence
However, the prime concerns of grassroots innovators are poor infrastructure, poverty, lack of access to market and consequently their inability to commercialize their innovation [6]. The remote locations of most grassroots innovators make it further inconvenient to recognize their innovation and convert GRI into the commercial scale $[7,8]$. At the grassroots level, the lack of appropriate information and lack of adequate financial support drive them into a cycle of poverty trap and unemployment [9]. In this regard, ICT plays a significant role to help grassroots innovators connect to sources of essential information and market opportunities [4, 10]. Hence, the main aim of the paper is to highlight the importance of ICT for GRI and conduct an empirical study in a way that it can be identified as attractive and significant by researchers and practitioners.

The literature on ICT-enabled development has emphasized largely on the performance improvement of SMEs and MNCs by using online procurement, production, and marketing system $[11,12]$. Emerging trends in the digitized era have placed ICT at the pioneering position for social and economic development of the people who belong to the base of the economic pyramid or to the higher layers of the 
innovation pyramid [13]. The literature on GRI also supports the importance of grassroots innovation for entrepreneurship development [3]. Many researchers have asserted that the ICT has a major role to play in exploring the innovation potential of grassroots innovators into successful entrepreneurial venture [3, 10]. However, an empirical study on the role of ICT to facilitate GRI and convert GRI practices into entrepreneurship is scant in literature. Therefore, this research believes that it is worthwhile and interesting to explore how the use of ICT can help in transforming grassroots innovation into entrepreneurial success in Indian context.

\section{Litearure review}

\subsection{Grassroots innovation (GRI)}

GRI is defined as a network of grassroots innovators and organizations generating an innovative bottom-up solution that responds to local circumstances and basic needs of grassroots communities to achieve sustainable development $[14,15]$. The feature of this innovation is different from the mainstream innovation, as GRI arises mainly from the grassroots innovators who are economically poor but knowledge-rich [5]. GRI is the result of continuous efforts by the grassroots innovators in terms of trial and error, developing new practices, learning and experimentation [15]. GRI is defined as a process of generating innovative solutions by grassroots innovators in response to their local problems, while giving importance to the interest and value of grassroots communities involved [8, 16]. Learning is regarded as a vital element in the process of GRI. Learning provides GRI the opportunities to acquire new knowledge and skill through synthesis of information, knowledge, and experience. The new learning approach increases awareness about best practices and develop skills that add values in existing products or services [17].

According to Gupta [4], GRI is a unique concept in having environment-friendly solutions to the local problems of grassroots communities. Furthermore, it is noted that networking is vital for GRI to receive monetary and non-monetary resources from the government organizations, non-government organization and communities $[14,18]$. It is also evident that success of GRI depends on the level of socio-economic exchange between the network actors that facilitate grassroots development. GRI's key feature is the ability to utilize traditional knowledge, grassroots ingenuity and local resources for grassroots development. As per Smith et al [17], GRI is viewed as a clutch of technologies of social inclusion, generating a valuable store of knowledge in production, nurturing the local ingenuity, empowering the local community and economic transformation process. In a nutshell, the GRI is characterized in three key features: new learning practices, local solution and networking capabilities.

\subsection{Grassroots innovation (GRI) and entrepreneurship}

The essence of the GRI is the process of innovation by which the grassroots people such as the rural people, the marginalized communities and the indigenous tribes in rural and semi-urban areas can alter their economic destitution and access a better quality of life [18, 19]. Grassroots innovators have the potential for innovations born out of necessity, but they require resources to cmmercialize that innovation or its products $[6,20]$. With the availability of information access, grassroots innovators are enabled to use market and government information, technology to scale up or even to turn these innovations into commercially viable entities. Until now, a number of GRIs have been commercialized or been successfully scaled up in developing countries [5]. There are few cases where GRIs were transformed into entrepreneurial activities by increasing their product value to match market demand and by increasing market interaction to facilitate better commericialization [21]. The design drivers of GRI include market driven local necessity, effective use of available local resources and long term social sustainability as crucial to entrepreneurship development and essential for successful scaling up of GRI [22, 23].

The entrepreneurial success of a grassroots innovator depends on individual's perception of entrepreneurial activities [24]. In entrepreneurship literature, entrepreneurial success is measured with respect to business, economic, psychological, and social indicators [24, 25]. A measure of entrepreneurial success of entrepreneurs or innovators quantifies economic and non-economic benefits of their entrepreneurial activities in grassroots context [26]. Fisher et al [24] proposed personal and business performance indicators as measures of entrepreneurial success. The economic performance indicators include the entrepreneur's level of satisfaction and fulfillment of personal expectations with respect to business growth and economic benefits. The non-economic performance indicators measure percentage contribution of the firm in fulfilling their social responsibility towards the society and community [26].

\subsection{Grassroots innovation (GRI), ICT and entrepreneurship}

Information and communication technologies (ICT) play a vital role in addressing grassroots' challenges and offering opportunities to introduce grassroots products and services into national and international markets [10]. So far, the the available literature on ICT and its potential role in creating entrepreneurial opportunities for grassroots innovators are scanty. ICT promises incremental changes in all aspects of grassroots activities, including knowledge dissemination, economic practices, communities' engagement, social and business interaction [13]. ICT acts as the foundation for the entrepreneurial development of grassroots innovators 
by accumulating traditional and global knowledge. According to Seyfang and Smith [14], GRI is concerned with a range of mechanisms that use knowledge and grassroots ingenuity, in order to resolve the problems of grassroots innovators. As an important driver for entrepreneurship development of grassroots innovators, ICT support is required to advance the wellbeing of knowledge-rich grassroots entrepreneurs [15]. In this respect, ICT deployment has prospered the grassroots knowledge, skill and local resources in a meaningful way. It aids in shifting grassroots' gaze and align their skills that magnify the efforts of grassroots innovators and create new entrepreneurial opportunity $[3,27]$. As we further discuss, the question that what could be the critical influential parameters that effect the conversion of GRI potential into entrepreneurial activity by scaling up individual activities. To address the above research gap, this paper is designed to estimate the moderating role of ICT on the relationship between grassroots innovation and entrepreneurial success in Indian context.

\section{Hypothesis development}

\subsection{New learning practice, ICT and entrepreneurship}

ICT represents a new path for learning, quite different from the traditional learning practices in many ways, such as accessing relevant market and financial information, and participating in entrepreneurial activities more competitively [22, 27]. ICT facilitates learning through online training and skill development on e-learning, e-banking, e-governance, community information platform for grassroots innovators to upgrade their knowledge and develop new entrepreneurial skills [27, 28]. Furthermore, ICT tools are used for social and institutional learning where experts and scientists are allowed to contribute in a bottom-up process to generate commercially viable GRI and promote entrepreneurship at grassroots level [3, 29]. ICT provides knowledge-based services as moderate input in the diffusion and conversion of GRI, which are seen as basic services in the fields of entrepreneurship and economic well-being [30]. ICT allows grassroots innovators to learn new technologies, develop skill and knowledge for entrepreneurship development [31]. By using ICT tools, grassroots innovators develop the critical and complex thinking that is required to create and capture the market opportunities. ICT based learning approach also enhances grassroots' cognitive skill and allows them to use the tools to interpret and evaluate information and to share the acquired knowledge and ideas across other communities [3]. This brings benefits to the grassroots innovators in terms of achieving economic and non-economic benefits from entrepreneurial activities. As more and more grassroots innovators use computer and mobile internet as sources of information and cognitive tools, the use of ICT for learning purpose becomes a part and parcel in the process of entrepreneurship development [32]. ICT nurtures the cognitive skill and innovation capability of the grassroots innovators as essential for grassroots livelihood, thus playing an important role as a moderator for entrepreneurial success [32, 33]. Based on the evidence presented as above, this paper formulates the hypothesis $\mathrm{H} 1$ and $\mathrm{H} 2$ as follows:

H1: Use of ICT moderates the relation between new learning practices and economic benefits from entrepreneurial success.

H2: Use of ICT moderates the relation between new learning practices and non-economic benefits from entrepreneurial success.

\subsection{Local solution, ICT and entrepreneurship}

ICT brings the knowledge and talent of grassroots innovators into a platform where they can be identified and acknowledged for their innovative solution and products. In India, Honey Bee network is being involved to scout, record and recognize the GRI [5]. In this case, ICTs facilitate to create an open database that contains various information regarding innovation of grassroots innovators as well as grassroots issues [29]. ICT widens the perspective of grassroots innovators in terms of identifying effective solutions to their problems, allowing to share their ideas with experts and other communities and eventually opens up new entrepreneurial opportunities [3, 33]. GRIs are designed to meet the local needs, where it requires to match the market demand for entrepreneurship development. In this context, ICT has been developing a knowledge ecosystem for less visible, yet innovative segment of society belonging to the bottom of the economic pyramid [2]. It enables grassroots innovators and knowledge producers to access market information. ICT provides rapid access to financial capital and transactions, thus fostering the potential to strengthen grassroots livelihood with which grassroots communities are able to formulate new ideas to cope up with market demand and adapt to market change for entrepreneurship development [33]. In addition to this, ICT assists in disseminating unique insights about how effective utilization of local resources can be achieved, and how to carefully consider the interest, value and economic needs of the grassroots communities [1, 27]. ICT provides an opportunity to integrate indigenous knowledge with technical information which adds a definitive competitive edge to the GRI that help for entrepreneurial success of grassroots innovators [10]. Based on the above facts, this paper formulates hypothesis $\mathrm{H} 3$ and $\mathrm{H} 4$ as follows:

H3: Use of ICT moderates the relation between local solutions and economic benefits from entrepreneurial success. 
H4: Use of ICT moderates the relation between local solutions and non-economic benefits from entrepreneurial success.

\subsection{Networking capabilities, ICT and entrepreneurship}

The majority of GRI journey has started off in a lonely and isolated fashion positioned in remote villages. In this context, ICT connects grassroots innovators with formal organizations, institutes, and market and facilitates them to create a network for transaction and relational exchange [14]. Here, the exchanges are derived by the value, the interest of communities and economic need of society. ICTenabled interventions such as mobile and internet assist grassroots innovators to re-frame their innovation activities by taking financial and market support [3, 31]. Subsequently, the grassroots innovators further take up innovation using ICT tools and convert their work into entrepreneurial activities. The moderation of ICT stimulates the sharing of knowledge and information and lays the concrete ground for continuity of relation and economic engagement through network development [13, 22]. ICT compensates for the lack of accessibility of information thus enabling grassroots innovators to access financial assistance and market information for opportunity recognition, commercialization and poverty alleviation. During the diffusion mode of GRI, ICT-based networking deal with the business and communities to scale up innovation [32]. ICT offers an opportunity to introduce new products and services related to handicraft skills, new ideas and traditional knowledge to the marketplace and simultaneously provide the economic and non-economic benefits to grassroots innovators [34]. ICT intervention provides an effective pathway to provide new life to declining traditional art forms of the grassroots innovators. To further encourage innovation, ICT-based network provides an open

Table 1. Sample characteristics.

\begin{tabular}{lcccc}
\hline \multirow{2}{*}{ Criteria } & S. & & & \\
& no & Sub-criteria & Frequency & Percentage \\
\hline Gender & 1.1 & Male & 179 & 45 \\
& 1.2 & Female & 221 & 55 \\
Type of & 2.1 & Organized & 154 & 28 \\
entrepreneurs & 2.2 & Unorganized & 246 & 72 \\
Age & 3.1 & $18-25$ & 70 & 21 \\
& 3.2 & $26-35$ & 129 & 36 \\
& 3.3 & $36-45$ & 118 & 25 \\
& 3.4 & $46-55$ & 69 & 15 \\
State & 3.5 & $55+$ & 14 & 2 \\
& 4.1 & Gujarat & 140 & 35 \\
& 4.2 & West Bengal & 220 & 55 \\
& 4.3 & Uttar & 40 & 10 \\
& \multicolumn{5}{c}{ Pradesh }
\end{tabular}

platform to explore the entrepreneurial opportunities for developing grassroots innovative products that are frugal, yet flexible and environment-friendly [14, 15]. Based on this discussion, we hypothesize as follows.

H5: Use of ICT moderates the relation between networking capability and economic benefits from entrepreneurial success.

H6: Use of ICT accessibility moderates the relation between networking capability and non-economic benefits from entrepreneurial success.

\section{Methodology}

In this study, the primary units of analysis were grassroots innovators who are involved in entrepreneurial activities. The statistical population variables considered in the questionnaire has covered sex, age, type of sector and regions (table 1). The study involved 400 grassroots entrepreneurs selected from the three Indian states: West Bengal, Gujarat, and Uttar Pradesh. These states are wellknown for diverse culture, religion and variety of geographical land. However, these states are home to a large number of artisans spread across the state. The majority of grassroots innovators dealt with handicrafts, handlooms, home-based small scale manufacturing, cottage industries, and food sector.

\subsection{Questionnaire survey}

In this study, the questionnaire was designed by referring to relevant literature on GRI, ICT and entrepreneurship development. Later on, the questionnaire was reviewed by three experts. The questionnaire was reformed while addressing the comments and suggestions from experts. Two grassroots entrepreneurs were involved in the brain storming which helped us in refining the text, technical phrases and sequence of questionnaire that further simplified its understanding and relevance to grassroots context. The refined questionnaire was used for data collection during the field survey. The data was collected using closeended questionnaire followed by face-to-face interview of grassroots innovators who involved in entrepreneurial activities. The resulting data included 400 entries out of the targeted 450. The deficiency of 50 entries is attributed to unwillingness of people, their disinterest, migration of minor section of people to other geographical location and occupations. The participants of the field survey were considered eligible those who fulfilled the following three criteria: (1) they must belong to the class of artisans from handloom, handicraft or cottage industry, (2) actively engaged in innovation process at grassroots level, (3) they possess knowledge and minimum acquaintance to the usage of ICT tools. 


\subsection{Measurement of variables}

A five point likert scale was used for this study. The scale was anchored with " $1 "=$ strongly disagree, " $2 "=$ moderately disagree, " 3 " = neutral agree, " $4 "=$ moderately agree and "5" = strongly agree. The questionnaire included the variables of GRI, the use of ICT and entrepreneurial success.

4.2a Measures of grassroots innovation (GRI): The variables of GRI as measured by following items such as GRI1: new learning practice to build capacity for mass involvement [15], GRI2: new learning practice to find low cost solutions [19], GRI3: new learning practice to create new entrepreneurial opportunities [8], GRI4: conversion of new ideas to action gives economic benefits [8], GRI5: new skill development to create new entrepreneurial opportunities [4], GRI6: new skill development to create new market opportunities [8], GRI7: new skill development for better utilization of available resources (GRI7) [18], GRI8: new way to solve problem should consider the interest and value of community [20], GRI9: adaption of new method/practice for better solution [4], GRI10: creation of solutions based on local state of affairs [20], GRI11: integration of new ideas and knowledge for better way to solve the problem [4], GRI12: relation with government organization that helps to access new market information and opportunity [35], GRI13: relation with government organizations that helps to involve more people in innovation process [8], GRI14: relation with NGOs that helps to involve more people in innovation process [35], GRI15: relation with private organizations that helps to access new market opportunity [35].

4.2b Measures of entrepreneurial success: The measure of entrepreneurial success is assessed through various entrepreneurial actions of grassroots innovators that enhance wealth by increasing their income through selling of product and exploitation of new market opportunities. In this study, the entrepreneurial success is measured by economic benefits and non-economic benefits of grassroots innovators from entrepreneurial activities [36]. The study includes variables of economic benefits as measured by following items: (1) I feel that I am running a successful business which creates new employment opportunities (EB1); (2) I am as ambitious now as my entrepreneurial activity (EB2); (3) I feel that my business is continually growing in market (EB3); I feel that my business is something that increases our profit (EB4). Furthermore, the non-economic benefits are measured by following items: (1) I think of my business as something that my community can become involved in and valued for their potential (NEB1); (2) As a small business I think my business help to enhance my social status through contributing to the wider community (NEB2); (3) I think of my business as something that promotes the art and culture-based innovative products (NEB3). 4.2c Measures of the use of ICT in grassroots context: ICT has progressively become an important platform for grassroots innovators in transforming GRI into entrepreneurial activities and economic opportunities [10]. ICT coupled with internet and mobile technology could help grassroots innovators to use the online database and marketing tools that assist in transferring GRI into entrepreneurial activities [37]. The variables of ICT in grassroots context are: (1) Use of ICT helps in adding commercial value to the product (ICT1); (2) Use of ICT help in accessing and sharing market information and services for entrepreneurial activities (ICT2); and (3) Use of ICT helps in accessing entrepreneurial opportunities offered by different agencies/institutes (ICT3).

\subsection{Data analysis}

This study was executed in three stages. Firstly, exploratory factor analysis was executed to derive the factors of grassroots innovation. Later on, confirmatory factor analysis was employed to confirm the structure of the derived factors. Lastly, the moderated structural equation modelling was used to analyse the moderating effect of the use ICT on the relationship between the factors of GRI and ES, respectively.

4.3a Exploratory factor analysis: Factor analysis is used to disclose the underlying structure of a set of variables related to grassroots innovation. The study expected a number of factors representing each group. It is assumed that the $n$ observed variables (the $A n$ ) that of the p subjects have been measured for each factor.

$$
\begin{array}{r}
A_{1}=\mu_{1}+\lambda_{11} F_{1}+\lambda_{12} F_{2}+\ldots \lambda_{1 a} F_{a}+e_{1} \\
A_{2}=\mu_{2}+\lambda_{21} F_{1}+\lambda_{22} F_{2}+\ldots \lambda_{2 a} F_{a}+e_{2} \\
\vdots \\
A_{n}=\mu_{n}+\lambda_{n 1} F_{1}+\lambda_{n 2} F_{2}+\ldots \lambda_{n a} F_{a}+e_{n}
\end{array}
$$

Equation (1) can be written in matrix form as

$$
\begin{aligned}
{\left[\begin{array}{c}
A_{1} \\
A_{2} \\
\vdots \\
A_{n}
\end{array}\right]=} & {\left[\begin{array}{c}
\mu_{1} \\
\mu_{2} \\
\vdots \\
\mu_{n}
\end{array}\right]+\left[\begin{array}{cccc}
\lambda_{11} & \lambda_{12} & \ldots & \lambda_{1 a} \\
\lambda_{21} & \lambda_{22} & \ldots & \lambda_{2 a} \\
\vdots & \vdots & \vdots & \vdots \\
\lambda_{n 1} & \lambda_{n 2} & \vdots & \lambda_{n a}
\end{array}\right]\left[\begin{array}{c}
F_{1} \\
F_{2} \\
\vdots \\
F_{a}
\end{array}\right] } \\
& +\left[\begin{array}{c}
e_{1} \\
e_{2} \\
\vdots \\
e_{n}
\end{array}\right]
\end{aligned}
$$

Where $A_{n}$ is observed variable, $\mu_{n}$ is mean, $\lambda_{n a}$ is cconstant, $F_{a}$ is "a" number of common factor and $e_{n}$ is an unobserved stochastic error terms. Hence, equation 2 can be written as 


$$
A_{n \times 1}=\mu_{n \times 1}+\Lambda_{n \times a} F_{a \times 1}+\varepsilon_{n \times 1}
$$

where $A_{n \times 1}$ is the vector of measurement, $\mu_{n \times 1}$ is the vector of means, $\Lambda_{n \times a}$ is the matrix of loadings, $F_{a \times 1}$ is "a" number of common factors, $\varepsilon_{n \times 1}$ is a vector of residuals. Here, $\mathrm{F}$ is an independent vector with each of its element having mean zero and standard deviation 1. Hence, $E(F)=0_{a \times 1}, E\left(F^{\prime} F\right)=\mathrm{I}_{a \times n}$ and $\operatorname{Cov}(\varepsilon)=E\left(\varepsilon^{\prime} \varepsilon\right)=\Psi_{p \times p}$

The orthogonal factor model is written as

$$
A_{i}-\mu_{i}=\lambda_{i 1} F_{1}+\lambda_{i 2} F_{2}+\ldots+\lambda_{i a} F_{a}+e_{i}
$$

In matrix form it can be written as

$$
Z_{n \times 1}=\Lambda_{n \times a} F_{a \times 1}+\varepsilon_{n \times 1}
$$

The correlation matrix for A can be written as

$$
\sum n \times n=\Lambda^{T} \Lambda+\Psi
$$

where $\sum n \times n$ is the correlation matrix of $Z_{n \times 1}$

The factor Score of derived factors is given by

$$
F=\left(\Lambda^{T} V^{(-1)} \Lambda\right)^{-1} \Lambda^{T} V^{-1}
$$

where, $V=\sum_{1}^{p} \frac{(X-\mu)^{2}}{l}, \mathrm{~V}$ is the diagonal matrix of the variances of the "l" unique factor scores

4.3b Confirmatory factor analysis: Confirmatory factor analysis is used to examine the degree to which responses on $\mathrm{n} \times 1$ vector of observed variables allocate a value of latent variables (s). It used to assess the effect of common method bias and to confirm the structure of the derived factors. The study is accomplished by estimating and assessing the loadings of each observed item used to tap features of the latent variable. That is, $A_{n}$ is the vector of observed responses projected by the latent variable $n$, which is represented as:

$$
\begin{aligned}
& A_{1}=\lambda_{11} \xi_{1}+\delta_{1} \\
& A_{2}=\lambda_{21} \xi_{1}+\delta_{2} \\
& A_{3}=\lambda_{32} \xi_{2}+\delta_{3} \\
& A_{4}=\lambda_{42} \xi_{2}+\delta_{4} \\
& A_{n}=\lambda_{n a} \xi_{a}+\delta_{n}
\end{aligned}
$$

In matrix form the equation (8) can be written as

$$
\left[\begin{array}{l}
A_{1} \\
A_{2} \\
A_{3} \\
A_{4} \\
A_{5} \\
A_{n}
\end{array}\right]=\left[\begin{array}{ccc}
\lambda_{11} & 0 & 0 \\
\lambda_{21} & 0 & 0 \\
\lambda_{31} & 0 & 0 \\
0 & \lambda_{42} & 0 \\
0 & \lambda_{52} & 0 \\
0 & 0 & \lambda_{n a}
\end{array}\right]\left[\begin{array}{l}
\xi_{1} \\
\xi_{2} \\
\xi_{a}
\end{array}\right]+\left[\begin{array}{l}
\delta_{1} \\
\delta_{2} \\
\delta_{3} \\
\delta_{4} \\
\delta_{5} \\
\delta_{n}
\end{array}\right]
$$

where $A_{n}$ is observed variable, $\lambda_{n a}$ is constant, $\xi_{a}$ is "a" number of common factor and $\delta_{n}$ is an unobserved stochastic error terms. Hence, the equation (9) can be rewritten as

$$
A=\Lambda \xi+\delta
$$

where $A$ is the vector of measurement, $\Lambda$ is the matrix of loadings, $\xi$ is "a" number of common factors and $\delta$ is a vector of residuals

4.3c Moderated structural equation model: In this study, moderated structural equation model was used to examine the effect of moderated latent factor on the relationship between the independent latent factor and dependent latent factor. The moderated structural equation model is executed by following three-step procedure recommended by Cortina et al [38] and Ping [39].

Step 1 Standardize all indicators for the independent variable A (factors of grassroots innovation, $S_{a l}, l \in F_{a}$ ) and Moderator B $\left(S_{p m}, m \in M_{p}\right)$ where $F_{a}$ is set of independent variable that indicates a specific independent factor, $M_{p}$ is set of variables that will indicate the moderator.

Step 2 Generate interaction term

$$
\xi_{a p}=\sum_{l \in F_{a}} S_{a l} \times \sum_{m \in M_{p}} S_{p m}
$$

In this paper, the use of ICT is considered as the only moderator. Thus, after substituting $p=1$, the above equation can be rewritten as,

$$
\xi_{a 1}=\sum_{l \in F_{a}} S_{a l} \times \sum_{m \in M_{1}} S_{1 m}
$$

Step 3 Fix the measurement property for interaction term "ap". The path from latent interaction $\mathrm{AB}$ to indicator "ap" can be written as,

$$
\lambda_{a p}=\sum_{l \in F_{a}} \lambda_{a l} \times \sum_{m \in M_{p}} \lambda_{p m}
$$

where $\lambda_{a l}$ is the path coefficient from latent independent factor A to its indicator $S_{a l}, l \in F_{a}, \lambda_{p m}$ is the path coefficient from latent moderator $\mathrm{B}$ to its indicator $S_{p m}, m \in M_{p}$,

$$
\begin{aligned}
\theta_{a p}= & \left(\sum_{l \in F_{a}} \lambda_{a l}\right)^{2} \times \operatorname{Var}(A) \\
& \times\left(\sum_{m \in M} \theta_{p m}\right)^{2}+\left(\sum_{m \in M} \lambda_{p m}\right)^{2} \times \operatorname{Var}(B) \times \sum_{l \in F_{a}} \theta_{a l} \\
& +\sum_{m \in M} \theta_{p m} \times \sum_{l \in F_{a}} \theta_{a l}
\end{aligned}
$$

where $\lambda_{a l}$ is the path coefficient from latent independent factor A to its indicator $S_{a l}, l \in F_{a}, \lambda_{p m}$ is the path coefficient from latent moderator $\mathrm{B}$ to its indicator $S_{p m}, m \in M_{p}, \theta_{a p}$ is random measurement error for interaction indicator $\xi_{a n} \mathrm{M} \theta_{a l}$ is the random measurement error 
of indicator $S_{a l}, l \in F_{a} \theta_{p m}$ is the random measurement error of indicator $S_{p m}, m \in M_{p}$.

In this paper, three models were designed to access the moderating effect of the use of ICT on the relationship between factors of GRI (three factors: new learning practice, local solutions and networking capabilities) and entrepreneurial success (economic benefits and non-economic benefits). The proposed models are described as follows: Model A represents the moderating effect of the use of ICT on the relationship between new learning practice and entrepreneurial success (economic benefits and non-economic benefits). Model B represents the moderating effect of the use of ICT on the relationship between local solution and entrepreneurial success (economic benefits and non-economic benefits). Model $\mathrm{C}$ represents the moderating effect of the use of ICT on the relationship between learning and entrepreneurial success (economic benefits and non-economic benefits).

\section{Result}

\subsection{Exploratory factor analysis}

The exploratory factor analysis was employed using SPSS. The factor analysis was used to derive the factors of grassroots innovation. The derived factors possessed a KMO value of 0.723 that exceed the standard recommended by Conway and Huffcutt [40]. Figure 1 shows the result of communalities, which is a measure of the amount of variance that the variables share with the other variables in the study. The extraction communalities are estimates of the variance in each variable accounted for by the factor. The High communalities $(>0.4)$ illustrate that the extracted factors explain most of the variance in the analysed variables. Based on this, 10 variables of grassroots innovation as shown in figure 1 were retained for further analysis.

In next stage, the principal component analysis was performed to convert a set of observed variable into a principal components which indicate the values of linearly unrelated variables. From the principal component analysis

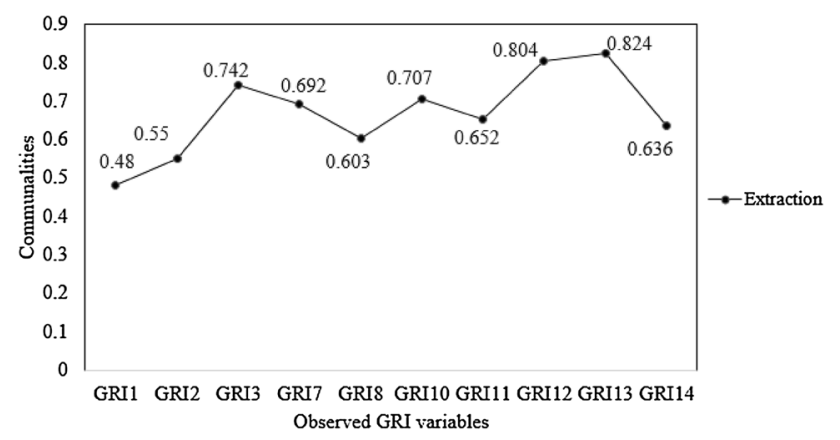

Figure 1. Communalities of observed variables of GRI. test, 3 factors of GRI were identified; these factors yielded a total variance of $66 \%$, exceed the standard value recommended by King [41]. Later on, the rotation converged in five iterations, where the original orders of the responses have been rearranged to reflect the order of factor structure. As table 2 shows the result of factor loading which illustrates that factors have a loading of more than 0.50 and each factor explained by more than one observed variable. The exploratory factor analysis revealed that there were three distinct factors that have a significant factor loading as indicated by the table 2 . We consider 10 variables associated with three factor solution as sufficient for the construct of GRI. We have labelled the following three factors: learning practice, localized problems, and networking capabilities. Later on, confirmatory factor analysis was executed to examine the potential influence of common method bias and to confirm the structure of derived factors.

\subsection{Measurement model}

The exploratory factor analysis revealed that there are three factors of GRI, namely learning practice, local solution and network capabilities. In this study, these three factors of GRI are considered as independent factors, the use of ICT considers as moderator and lastly, economic benefits from entrepreneurial success and non-economic benefits from entrepreneurial success considered as dependent factors. As table 3 shows, all the factors yielded Cronbach alpha values that exceed the acceptance standard of 0.7 recommended by Jin et al [42]. It shows that all constructs possessed satisfactory reliability. As table 4 illustrates that model A, B and $\mathrm{C}$ possess model fitness value such as the ratio of $\mathrm{C}$ MIN/DF is lowered the standard value 3; the value of CFI exceeded the standard value of 0.8 ; the value of root mean square error lowered the standard value of 0.08 . The value of normed fit index (NFI) and comparative fit index, all of which exceeded the standard value of 0.8 and the value of parsimony NFI which exceeded the standard value of 0.5 . These results indicate that a satisfactory model fit was achieved [43, 44].

Table 2. Rotated component matrix.

\begin{tabular}{lrrr}
\hline & \multicolumn{3}{c}{ Components } \\
\cline { 2 - 4 } Observed GRI variables & Factor 1 & Factor 2 & Factor 3 \\
\hline GRI3 & $\mathbf{. 8 5 9}$ & .013 & -.062 \\
GRI7 & $\mathbf{. 8 3 0}$ & .046 & -.018 \\
GRI2 & $\mathbf{. 6 9 4}$ & -.068 & .253 \\
GRI1 & $\mathbf{. 6 5 3}$ & .024 & .230 \\
GRI13 & .120 & .045 & $\mathbf{. 8 9 9}$ \\
GRI12 & .126 & .031 & $\mathbf{. 8 8 7}$ \\
GRI14 & .063 & .065 & $\mathbf{. 7 9 2}$ \\
GRI10 & .015 & $\mathbf{. 8 4 0}$ & .031 \\
GRI11 & .088 &. $\mathbf{7 9 7}$ & .098 \\
GRI8 & .080 & $\mathbf{. 7 7 2}$ & .001 \\
\hline
\end{tabular}


Table 3. Measurement model.

\begin{tabular}{|c|c|c|c|}
\hline Constructs & $\begin{array}{l}\text { Observed } \\
\text { variables }\end{array}$ & $\begin{array}{c}\text { Cronbach's } \\
\text { alpha }\end{array}$ & $\begin{array}{l}\text { Number of } \\
\text { items }\end{array}$ \\
\hline $\begin{array}{l}\text { New learning } \\
\text { practice (LP) }\end{array}$ & $\begin{array}{l}\text { GRI1, GRI2, } \\
\text { GRI3, GRI7 }\end{array}$ & .769 & 4 \\
\hline $\begin{array}{l}\text { Local solutions } \\
\quad \text { (LS) }\end{array}$ & $\begin{array}{c}\text { GRI8, } \\
\text { GRI10,GRI11 }\end{array}$ & .729 & 3 \\
\hline $\begin{array}{l}\text { Networking } \\
\text { capabilities } \\
\text { (NC) }\end{array}$ & $\begin{array}{c}\text { GRI 12,GRI13, } \\
\text { GRI14 }\end{array}$ & .801 & 3 \\
\hline $\begin{array}{l}\text { Economic benefits } \\
\text { (EB) }\end{array}$ & EB1, EB2, EB3 & .888 & 3 \\
\hline $\begin{array}{l}\text { Non-economic } \\
\text { benefits (NEB) }\end{array}$ & $\begin{array}{c}\text { NEB1, NEB2, } \\
\text { NEB3 }\end{array}$ & .912 & 3 \\
\hline Use of ICT & ICT1,ICT2,ICT3 & .949 & 3 \\
\hline
\end{tabular}

The structural equation modelling was carried out using AMOS. The moderated structural equation modelling was employed over the regression analysis because moderated regression analysis restricted the researchers to examining one dependent variable at a time. Furthermore, structural equation model (SEM) has a common feature which stipulates more accurate parameter estimates, more flexible and

Table 4. Model fitness value.

\begin{tabular}{lccccc}
\hline Model name & CMIN/DF & CFI & NFI & RFI & RMSEA \\
\hline Model A & 0.021 & 1.00 & 1.00 & .996 & .001 \\
Model B & 0.101 & 1.00 & .999 & .986 & .002 \\
Model C & 0.020 & 1.00 & 1.00 & .997 & .001 \\
\hline
\end{tabular}

higher statistical power. The hypothesized moderating effects were examined following the moderated SEM approach. Table 5 shows the value of regression weights.

Hypothesis 1 proposes that use of ICT moderates the relationship between new learning practices and economic benefits from entrepreneurial success. Figure 2 shows that interaction coefficient for new learning practice and use of ICT was significant $(\beta=0.18, \rho<0.001)$ which confirms its moderation effect. A partial moderation has occurred, as table 5 showed that one of the main effects was also significant. Therefore, going by the results hypothesis 1 is accepted. Hypothesis 2 proposes that use of ICT moderates the relationship between new learning practices and noneconomic benefits from entrepreneurial success. It is observed from figure 2 that, the interaction coefficient for new learning practice and use of ICT was not significant $(\beta=-0.01, \rho>0.05)$ showing that moderation has not occurred. Therefore, hypothesis 2 is not accepted as it is not well-supported by the results.

Hypothesis 3 proposes that use of ICT moderates the relationship between local solution and economic benefits from entrepreneurial success. Figure 3 shows that interaction coefficient for local solution and use of ICT was significant $(\beta=0.16, \rho<0.001)$. This shows its moderation effect. A partial moderation has occurred, as table 5 showed that one of the main effects was also significant. Since hypothesis 3 is supported by the results, it is accepted. Hypothesis 4 proposes that use of ICT moderates the relationship between local solution and non-economic benefits from entrepreneurial success. The finding

Table 5. Regression weights

\begin{tabular}{|c|c|c|c|c|c|}
\hline & Estimate & S.E. & C.R. & $\mathrm{P}$ & Significance \\
\hline \multicolumn{6}{|l|}{ Model A } \\
\hline $\mathrm{LP} \rightarrow \mathrm{EB}$ & .137 & .047 & 2.936 & .003 & Yes \\
\hline $\mathrm{LP} \times \mathrm{ICT} \rightarrow \mathrm{EB}$ & .180 & .050 & 3.600 & $* * *$ & Yes \\
\hline $\mathrm{ICT} \rightarrow \mathrm{EB}$ & .295 & .047 & 6.281 & $* * *$ & Yes \\
\hline $\mathrm{LP} \rightarrow \mathrm{NEB}$ & .146 & .050 & 2.936 & .003 & Yes \\
\hline $\mathrm{LP} \times \mathrm{ICT} \rightarrow \mathrm{NEB}$ & -.097 & .053 & 1.816 & .069 & No \\
\hline $\mathrm{ICT} \rightarrow \mathrm{NEB}$ & -.017 & .050 & -.337 & .736 & No \\
\hline \multicolumn{6}{|l|}{ Model B } \\
\hline $\mathrm{LS} \rightarrow \mathrm{EB}$ & .233 & .046 & 5.031 & $* * *$ & Yes \\
\hline $\mathrm{LS} \times \mathrm{ICT} \rightarrow \mathrm{EB}$ & .163 & .049 & 3.324 & $* * *$ & Yes \\
\hline $\mathrm{ICT} \rightarrow \mathrm{EB}$ & .248 & .046 & 5.372 & $* * *$ & Yes \\
\hline $\mathrm{LS} \rightarrow \mathrm{NEB}$ & -.088 & .054 & -1.636 & .102 & No \\
\hline $\mathrm{LS} \times \mathrm{ICT} \rightarrow \mathrm{NEB}$ & .053 & .051 & 1.046 & .295 & No \\
\hline $\mathrm{ICT} \rightarrow \mathrm{NEB}$ & -.039 & .051 & -.768 & .443 & No \\
\hline \multicolumn{6}{|l|}{ Model C } \\
\hline $\mathrm{NC} \rightarrow \mathrm{EB}$ & .073 & .047 & 1.567 & .117 & No \\
\hline $\mathrm{NC} \times \mathrm{ICT} \rightarrow \mathrm{EB}$ & .197 & .050 & 3.920 & $* * *$ & Yes \\
\hline $\mathrm{ICT} \rightarrow \mathrm{EB}$ & .285 & .047 & 6.046 & $* * *$ & Yes \\
\hline $\mathrm{NC} \rightarrow \mathrm{NEB}$ & .272 & .048 & 5.657 & $* * *$ & Yes \\
\hline $\mathrm{NC} \times \mathrm{ICT} \rightarrow \mathrm{NEB}$ & -.074 & .052 & -1.438 & .150 & No \\
\hline $\mathrm{ICT} \rightarrow \mathrm{NEB}$ & -.017 & .048 & -.356 & .722 & No \\
\hline
\end{tabular}




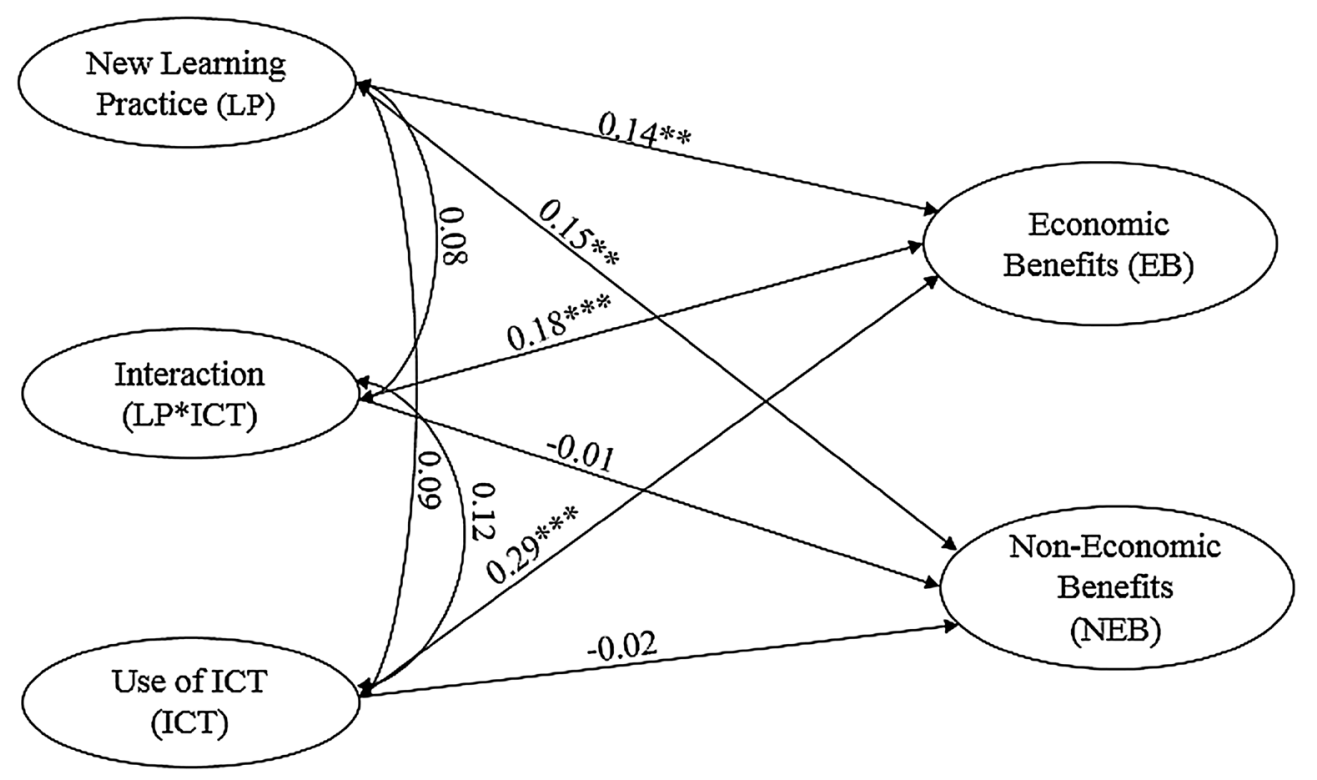

Figure 2. Moderating effect of ICT on the relationship between LP and ES (EB+NEB).

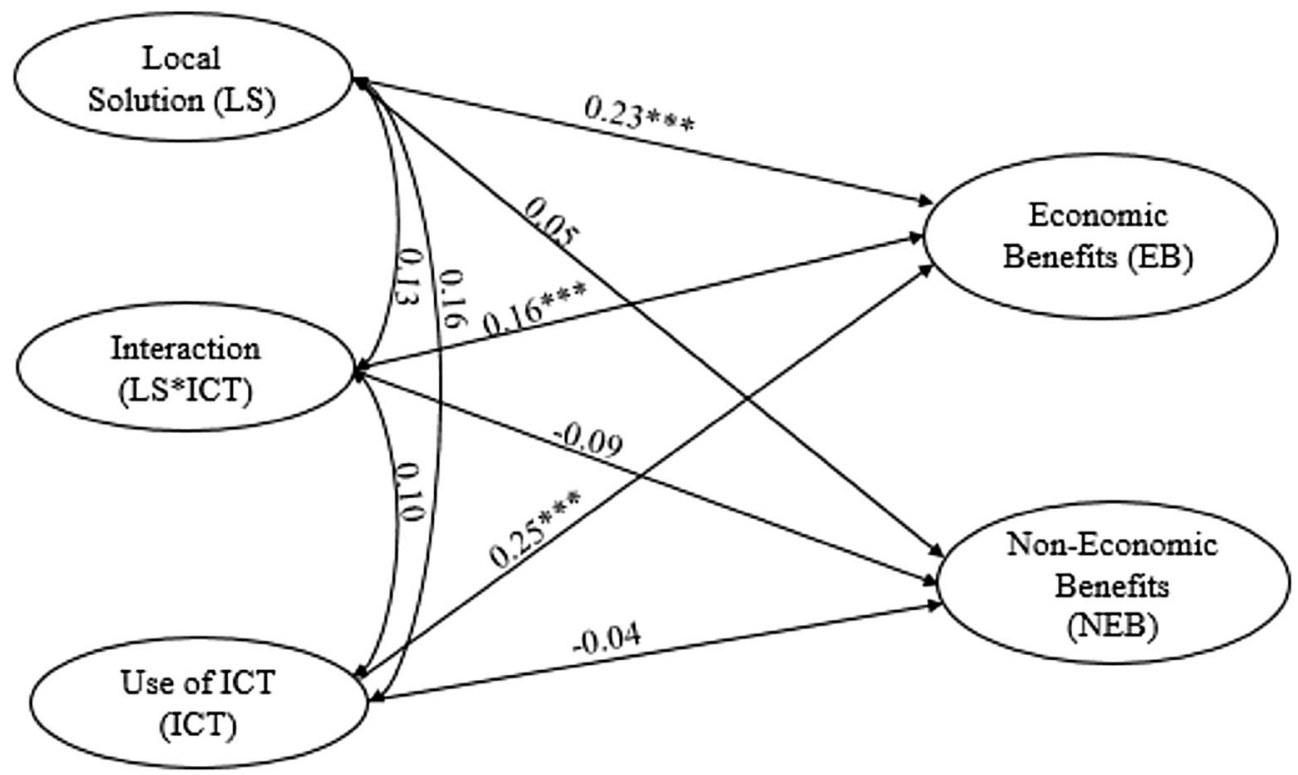

Figure 3. Moderating effect of ICT on the relationship between LS and ES (EB+NEB).

presented in figure 3 illustrates that, the interaction coefficient for networking capabilities and use of ICT was not significant $(\beta=-0.09, \rho>0.05)$. It shows that moderation has not occurred. Therefore, hypothesis 4 is not accepted as it lacks statistical support.

Hypothesis 5 proposes that use of ICT moderates the relationship between networking capabilities and economic benefits from entrepreneurial success. It can be inferred from figure 4 that the moderation effect of ICT has a significant effect on the relationship between networking capabilities and economic benefits, with a path co-efficient value $\beta=0.20$ at 0.001 level of significance showing the effect of its moderation. Therefore, hypothesis 5 being supported by the results is accepted. Hypothesis 6 proposes that use of ICT moderates the relationship between networking capabilities and non-economic benefits from entrepreneurial success. The finding presented in figure 4 illustrates that, the interaction coefficient for networking capabilities and use of ICT was not significant $(\beta=-0.07$, $\rho>0.05)$ indicating that moderation has not occurred. Therefore, hypothesis 6 being not supported by the results is not accepted. 


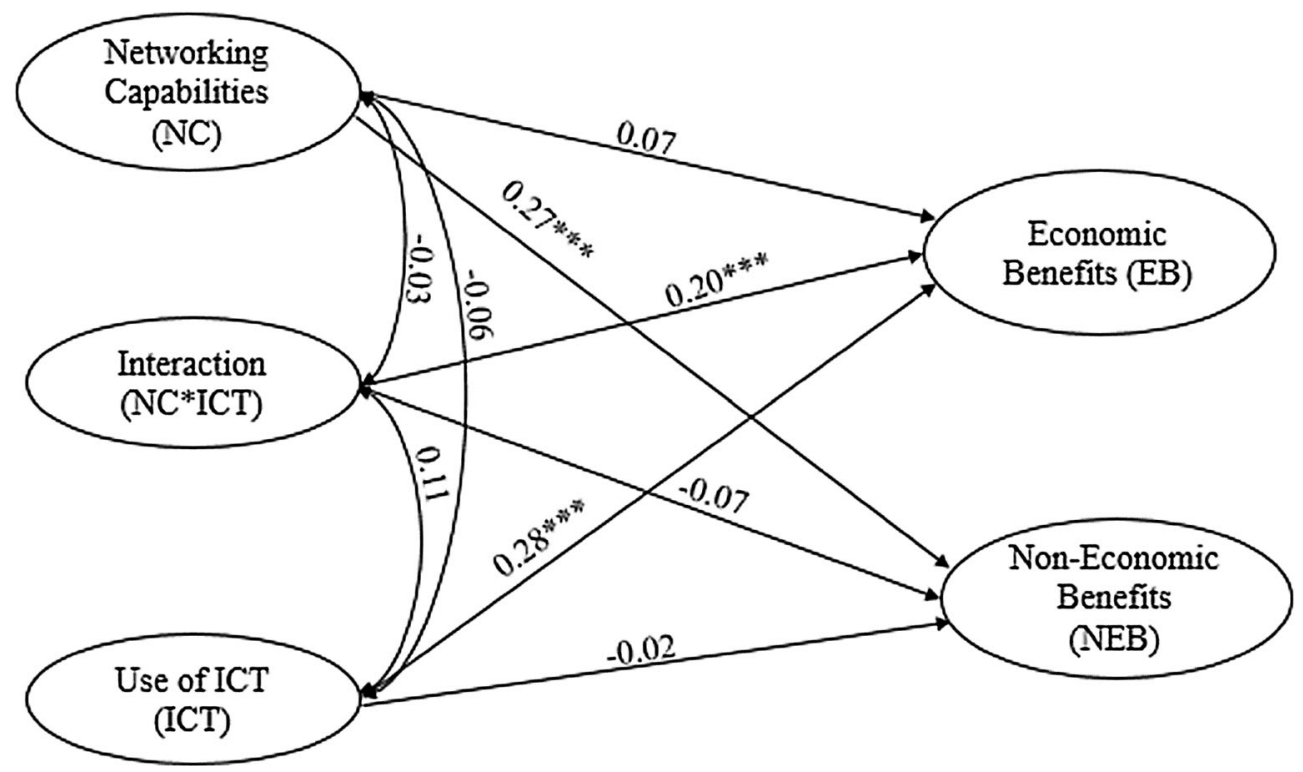

Figure 4. Moderating effect of ICT on the relationship between NC and ES (EB+NEB).

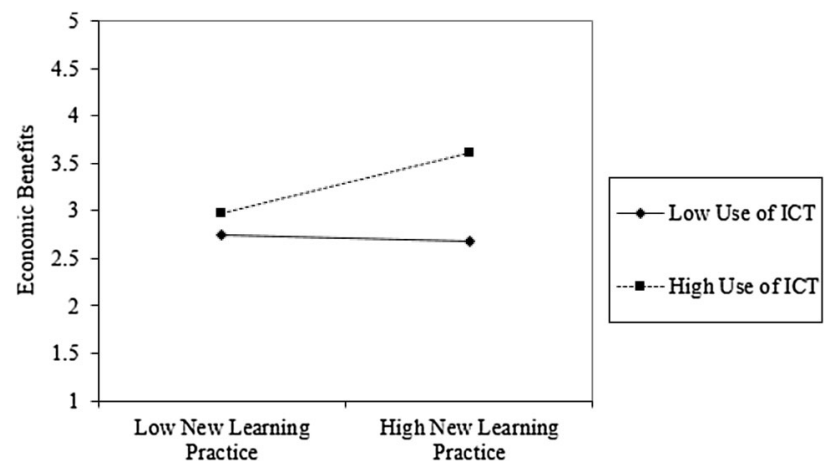

Figure 5. Interactions between new learning practice and the use of ICT on entrepreneurial success.

The study revealed that the use of ICT moderates the relationship between GRI and economic benefits from entrepreneurial success. However, it is also crucial to understand the relationship of factors of GRI and ecomonic benefits with respect to level of use of ICT. A simple slopes test was employed to further analyse the moderation effect of the use of ICT on LP-EB relationship. Figure 5 plots the interaction, which shows that the relationship between new learning practice and economic benefits of entrepreneurial success is stronger when use of ICT is high. This supports Hypothesis 1 . The analysis further indicates that the relationship between new learning practice and economic benefits of entrepreneurial success is weaker when the use of ICT is low.

Furthermore, the results have revealed that use of ICT will moderate the positive relationship between new learning practice and economic benefits, where the

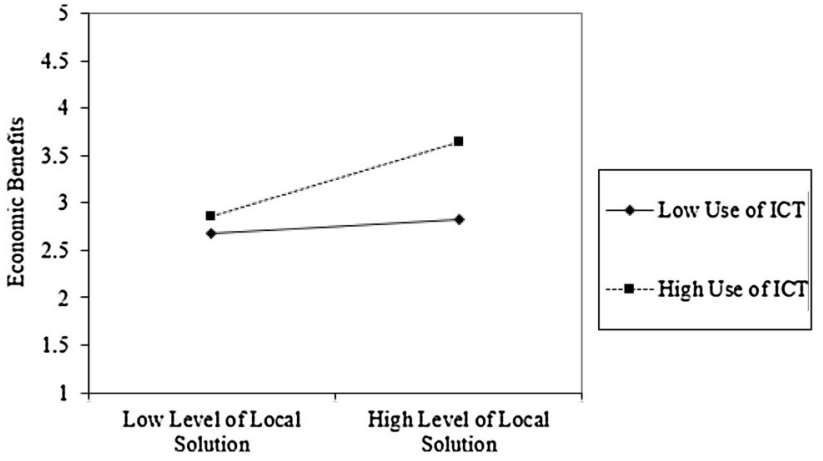

Figure 6. Interactions between local solution and the use of ICT on entrepreneurial success.

relationship is stronger when ICT accessibility is high $(\beta=0.257, \mathrm{t}=3.587, \mathrm{p}<0.001)$.

It can be interfered from figure 6 that the positive relationship between local solution and economic benefits of entrepreneurial success intensifies when use of ICT is high. The simple slope test is used to provide further support. The relationship between local solution and economic benefits from entrepreneurial success was weaker when the use of ICT is low. Hence, Hypothesis 3 is supported. The results revealed that use of ICT will moderate the positive relationship between local solution and economic benefits of entrepreneurial success, where the relationship will be stronger when use of ICT is high $(\beta=0.226, t=4.880$, $\mathrm{p}<0.001$ ).

Figure 7 plots the interaction and shows that the positive relationship between networking capabilities and economic benefits from entrepreneurial success intensifies when the use of ICT is high. The simple slope test is again used to 


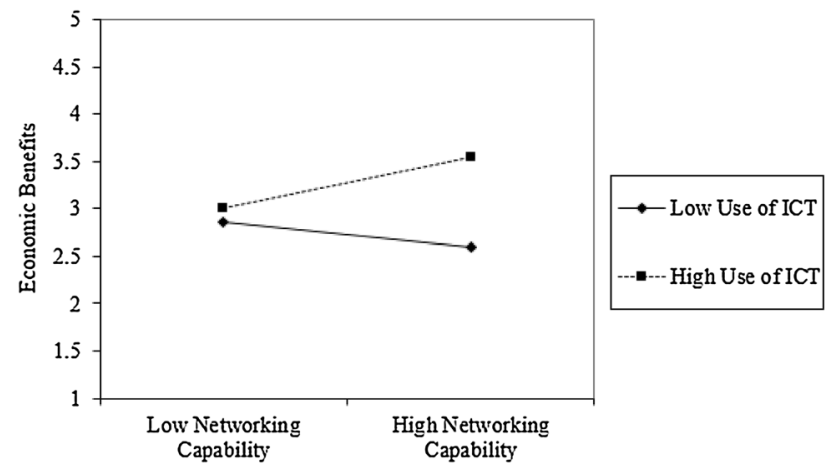

Figure 7. Interactions between networking capabilities and the use of ICT on entrepreneurial success.

offer further support. The relationship between networking capabilities and economic benefits from entrepreneurial success was negative where use of ICT is low. Furthermore, the results revealed that use of ICT will moderate the positive relationship between networking capabilities and economic benefits from entrepreneurial success, where the relationship will be stronger when use of ICT is high $(\beta=0.204, \mathrm{t}=4.501, \mathrm{p}<0.001)$.

\section{Discussion}

ICT-enabled GRI has received much research attention as an important mechanism for entrepreneurship development. The scope to improve the livelihood of grassroots innovators lies in the opportunities offered by ICT by opening up of new horizons in relevant and useful information [3]. In the grassroots context, the fundamental concern of ICT is to recognize the existing challenges of the grassroots innovators and resolve their issues through GRI and its affiliation with entrepreneurial success. Based on exploratory factor analysis, the study revealed three significant factors of GRI are new learning practice, local solution and networking capabilities.

This study offers three findings. First, the study reveals that the use of ICT partially moderates the relationship between new learning practice and economic benefits from entrepreneurial success. This finding extends the understanding with respect to the influence of ICT on GRI towards entrepreneurship development. The finding is supported by the work of Pigg and Crank [31], where it is said that ICT has the potential of bringing ideas, information, and knowledge of the grassroots innovators from the most isolated and remote places, and commercialize them to the world beyond their village or town. Thus, ICT allows grassroots innovators to explore and exploit their ideas, knowledge or experience with the other communities as well as with the rest of the country. However, in a parallel part of this study, it is revealed that use of ICT does not moderate the relationship between new learning practice and non-economic benefits from entrepreneurial success. The potential reasons for this might be due of lack of knowledge and orientation of grassroots innovators regarding societal concern of the entrepreneurial activities. In India, most of the grassroots innovators get motivated for entrepreneurship with desire to reap economic benefits by commercializing innovative products or service. Hence, according to the study the use of ICT is overlooked by grassroots innovators for non-economic benefits.

Second, the results revealed that the use of ICT partially moderates the relationship between local solution and economic benefits from entrepreneurial success. This is a new finding in the literature of grassroots innovation. It was asserted by many scholars that ICT plays an important role for commercializing and scaling up of the local solution into the commercial viable products. ICT builds competitive and healthy space for grassroots development, where grassroots innovators can enhance their skill and knowledge implementing more effective local solutions by utilizing grassroots resources in a meaningful way. In this regard, the use of ICT helps grassroots innovators to explore new opportunities that add value to their innovative product or services and simultaneously provide economic benefits $[14,22]$. However, this study found that the use of ICT does not moderate the relationship between local solution and non-economic benefits from entrepreneurial success. It might be because of the use of ICT is closely linked to the ability and knowledge of the grassroots innovators to adjust with market demand and to reform their solution or innovation. A poor economic condition is more likely to lead grassroots entrepreneurs to use the ICT, as a way to strengthen their economic performance. Grassroots entrepreneurs often use ICT to make their efforts and investment to achieve economic benefits, hence the non-economic benefits of the use of ICT would be limited.

Finally, the results draw attention to the moderating role of ICT on the relationship between networking capabilities and economic benefits from entrepreneurial success. In support of this, Honey Bee Network is also concerned with helping grassroots innovators by creating appropriate platform where grassroots innovators can identify and build networks, deeply engage and nurture it well, so that they come out with new entrepreneurial opportunities. Grassroots innovators use ICT to overcome geographical barriers and make relationship with government and non-governmental organizations that can lead to conversion of their unique skill and innovation into entrepreneurial activities. It can lead to build grassroots capability for entrepreneurship and enhance economic benefits. The results also revealed that the use of ICT does not moderate the relationship between networking capabilities and non-economic benefits from entrepreneurial activities. The possible reason might be due the lack of the awareness among the grassroots innovators on how ICT can be used to generate non- 
economic benefits from commercialization of innovative products. Furthermore, it is mentioned by many researchers that the use of ICT alone cannot be sufficient to provide non-economic benefits. Skill development, awareness creation and taking stock of relevant information are necessary elements to make ICT platform achieve its projected role.

\section{Conclusions}

In this study, the moderated structural equation modelling was used to analyse the moderating role of ICT on GRI-ES relationship in Indian context. This study has made several contributions to academic literature investigation on grassroots innovation, ICT and entrepreneurship development. ICT is often mentioned as a key moderator for entrepreneurship development but the areas of influence that prompt entrepreneurial activities of grassroots entrepreneurs are not always clear. This study highlights how ICT works as moderator in transforming innovation of grassroots entrepreneurs into entrepreneurial success. The findings revealed that ICT partially moderates the relationship of new learning practices with economic benefits and in the same way it partially moderates the relationship of local solution with the economic benefits. However, the study revealed that ICT does not moderate the relationship of new learning practices with non-economic benefits and in the same way it does not moderate the relationship that connects local solution with non-economic benefits. Furthermore, the finding of the study indicates that ICT moderates the relationship connecting networking capabilities with economic benefits, but it does not moderate the relationship that connects networking capabilities with noneconomic benefits. The study suggested that ICT-enabled GRI have more influence in creating and scaling up the grassroots innovation to potential and commercially viable entrepreneurial activities.

The findings also have implications for GRI practitioners and policy makers particularly in India and other emerging economies. The study could be used in different contexts and implemented in other parts of the word. The greater the use of ICT by grassroots innovators, higher the number of conversions from GRI into entrepreneurial activities can be observed. Hence, the policy makers and different organizations should emphasise on the use ICT for grassroots development. The government organizations and education institutions should use ICT-based platform and promote grassroots innovators to use ICT for sharing their local solution, traditional knowledge, get assistance and information and in developing connections with grassroots innovators and experts because ICT helps them to access information and opportunities which is crucial to succeed. It is but obvious that as all empirical studies have their own limitations, this study does have some limitations. One, the study is executed in Indian context, the finding might be
Indian context-specific. Future studies could be executed in other countries with the perspective to examine and extend the generalizations of the findings to broader domains of grassroots innovators.

\section{References}

[1] Subba Rao S 2004 Role of ICTs in India's rural community information systems. Info 6(4): 261-269

[2] Tarafdar M, Anekal P and Singh R 2012 Market development at the bottom of the pyramid: examining the role of information and communication technologies. Inf. Technol. Dev. 18(4): 311-331

[3] Maurya N, Kumar V, Patel R, Mahanta H and Gupta A 2014 ICTs in support of grassroots innovation. Inf. Technol. Inter. Dev. 10(1): 21-25

[4] Gupta A K 2013 Tapping the Entrepreneurial Potential of Grassroots Innovation. Stanford Social Innovation Review. Special Supplement on Innovation for a Complex World. Summer. 11(3): 18-20

[5] Gupta A K 2006 From sink to source: the Honey Bee Network documents indigenous knowledge and innovations in India. Innovations 1(3): 49-66

[6] Joshi R G, Chelliah J and Ramanathan V 2015 Exploring grassroots innovation phenomenon through the lived experience of an Indian grassroots innovator. South Asian J. Global Bus. Res. 4 (1): 27-44

[7] De Keersmaecker A, Parmar V, Kandachar P, Baelus C and Vandenbempt K 2012 Towards Scaling Up Grassroots Innovations in India: a Preliminary Framework. In: UNESCO Chair International Conference Technologies for Sustainable Development: A Way to Reduce Poverty? EPFL, Lausanne, Switzerland, pp. 29-31

[8] Gupta A K 2012 Innovations for the poor by the poor. Int. J. Technol. Learn. Innov. Dev. 5(1/2): 28-39

[9] Pathak R 2008 Grass-root creativity, innovation, entrepreneurialism and poverty reduction. Int. J. Entrep. Innov. Manag. 8(1): 87-98

[10] Cecchini S and Scott C 2003 Can information and communications technology applications contribute to poverty reduction? Lessons from rural India. Inf. Technol. Dev. 10(2): 73-84

[11] Chowdhury S K 2006 Investments in ICT-capital and economic performance of small and medium scale enterprises in East Africa. J. Int. Dev. 18(4): 533-552

[12] Corea S 2007 Promoting development through information technology innovation: The IT artifact, artfulness, and articulation. Inf. Technol. Dev. 13(1): 49-69

[13] Gupta A, Kothari B and Patel K 2000 Networking knowledge-rich, economically poor people. Information and communication technology in rural development: case studies from India. Washington, DC: World Bank Institute, pp. 84-97

[14] Seyfang G and Smith A 2007 Grassroots innovations for sustainable development: Towards a new research and policy agenda. Environ. Politics 16(4): 584-603

[15] Hossain M 2016 Grassroots innovation: a systematic review of two decades of research. J. Clean. Prod. 137: 973-981 
[16] Bhaduri S and Kumar H 2011 Extrinsic and intrinsic motivations to innovate: tracing the motivation of 'grassroot' innovators in India. Mind \& Soc. 10(1): 27-55

[17] Smith A, Fressoli M and Thomas H 2014 Grassroots innovation movements: challenges and contributions. J. Clean. Prod. 63: 114-124

[18] Kumar V, Chand V S, Zhang L, Odora Hoppers C A, Zhang W, Esders M and Hupta A K 2013 Grassroots Innovations for Inclusive Development: need for a Paradigmatic Shift. Vikalpa. 38(3): 103-107

[19] Pathak R 2008 Grass-root creativity, innovation, entrepreneurialism and poverty reduction. Int. J. Entrep. Innov. Manag. 8(1): 87-98

[20] Martin C J, Upham P and Budd L 2015 Commercial orientation in grassroots social innovation: insights from the sharing economy. Ecol. Econ. 118: 240-251

[21] Rahemtulla H A, Haklay M and Longley P A 2008 A mobile spatial messaging service for a grassroots environmental network. J. Locat Based Serv. 2(2): 122-152

[22] Baliamoune-Lutz M 2003 Analysis of the Determinants and Effects of ICT Diffusion in Developing Countries. Inf. Technol. Dev. 10(3): 151-169

[23] Ghosh M and Ghosh I 2009 ICT and information strategies for a knowledge economy: the Indian experience. Program. 43(2): 187-201

[24] Fisher R, Maritz A and Lobo A 2014 Evaluating entrepreneurs' perception of success: development of a measurement scale. Int. J. Entrep. Behav. Res. 20(5): 478-492

[25] Bonet F P, Armengot C R and Martin M A G 2011 Entrepreneurial Success and Human Resources. Int. J. Manpower. 32(1): 68-80

[26] Shepherd D A and Patzelt H 2011 The New Field of Sustainable Entrepreneurship: Studying Entrepreneurial Action Linking "What Is to Be Sustained" With "What Is to Be Developed". Entrepr. Theory Pract. 35(1): 137-163

[27] Huggins R R and Izushi H 2002 The Digital Divide and ICT Learning in Rural Communities: Examples of Good Practice Service Delivery. Local Econ. 17(2): 111-122

[28] Kanungo A. 2004 On the emancipatory role of rural information systems. Inf. Technol. People. 17(4): 407-422

[29] Pigg K E and Crank L D 2005 Do Information Communication Technologies Promote Rural Economic Development? Community Dev. 36(1): 65-76

[30] Puri S K and Sahay S 2007 Role of ICTs in participatory development: an Indian experience. Inf. Technol. Devel. 13(2):133-160
[31] Kopparapu S K and Saxena V 2014 Identifying the best market to sell: a cost function formulation. Sadhana 39(6): 1409-1423

[32] Carty V 2010 New information communication technologies and grassroots mobilization. Inf. Commun. Soc. 13(2): 155-173

[33] Galloway L, Mochrie R and Deakins D 2004 ICT enabled collectivity as a positive rural business strategy. Int. J. Entrep. Behav. Res. 10(4): 247-259

[34] Reinsberger K, Brudermann T, Hatzl S, Fleiß E and Posch A 2015 Photovoltaic diffusion from the bottom-up: analytical investigation of critical factors. Appl. Energy. 159: 178-187.

[35] Singh S H and Bhowmick B 2016 Innovation Network for Entrepreneurship Development in Rural Indian Context: Exploratory Factor Analysis. Int. J. Innov. Technol. Manag. 13(4): 1-10

[36] Rauch A and Frese M 2000 Psychological approaches to entrepreneurial success. A general model and an overview of findings. In: Cooper C L and Robertson I T (Eds.) International Review of Industrial and Organizational Psychology. Chichester: Wiley, pp. 101-142

[37] Kuriyan R, Ray I and Toyama K 2008 Information and communication technologies for development: The bottom of the pyramid model in practice. Inf. Soc. 24(2): 93-104

[38] Cortina J M, Chen G and Dunlap W P 2002 Testing Interaction Effects in LISREL: Examination and Illustration of the Available Procedures. Organ. Res. Methods 4 (4): 324-360.

[39] Ping R A 1995 A Parsimonious Estimating Technique for Interaction and Quadratic Latent Variables. J. Market. Res. 32: $336-347$

[40] Conway J M and Huffcutt A I 2003 A review and evaluation of exploratory factor analysis practices in organizational research. Organ. Res. Methods. 6: 147-168

[41] King L J 1969 Statistical Analysis in Geography. Englewood Cliffs, N.J.: Prentice-Hall

[42] Jin X H, Doloi H and Gao S Y 2007 Relationship-based determinants of building project performance in China. Constr. Manag. Econ. 25: 297-304

[43] Conway E, Fu N, Alfes K and Bailey C 2016 Demands or resources? The Relationship between HR Practices, employee engagement, and emotional exhaustion within a hybrid model of employment relations. Human Resour. Manag. 55(5): 901-917

[44] Shanmugapriya S and Subramanian K 2015 Structural equation model to investigate the factors influencing quality performance in Indian construction projects. Sadhana 40(6): 1975-1987 